Pre-print version of: Harmer, E. and Lumsden, K. (2019) 'Introduction: Online Othering.' In: K. Lumsden and E. Harmer (eds) Online Othering: Exploring Violence and Discrimination on the Web. Basingstoke: Palgrave Macmillan.

\title{
Online Othering: An Introduction
}

\section{Emily Harmer and Karen Lumsden}

\begin{abstract}
This chapter provides an overview of the rapidly changing social and political context which is driving a contested social media landscape, and explores examples of othering and discrimination propagated and encountered by individuals online and in social media contexts and cultures. After providing an overview of literature on 'othering', we outline our concept of 'online othering' which problematizes and analyses the dichotomy presented between real and virtual space(s) by exploring the motivations behind othering behaviours and the impact this has on the targets of online abuse. It also explores the extent to which ICTs facilitate and exacerbate traditional offline offences (such as domestic abuse and stalking). Finally, we consider various responses to 'online othering' which recognise its oppositional nature and the agency of the othered.
\end{abstract}

Keywords: abuse; discrimination; internet; online othering; othering; social media

\section{Introduction}

In this introductory chapter we set the scene for the edited collection by first outlining the social, political and cultural contexts which shape and seep into online communications including 'Trumpism' in the United States, 'Brexit' in the United Kingdom, and the related rise of the 'Alt-Right'. We then review studies of discrimination, harassment and hate on the web including examples of flaming, trolling, misogyny, racism and Islamophobia, and the ways in which political organisations, activists and feminists have resisted these toxic online 
Pre-print version of: Harmer, E. and Lumsden, K. (2019) 'Introduction: Online Othering.' In: K. Lumsden and E. Harmer (eds) Online Othering: Exploring Violence and Discrimination on the Web. Basingstoke: Palgrave Macmillan.

behaviours and discourses. We develop and outline our concept of 'online othering', situating our discussion within an overview of sociological literature and social theories on 'othering', 'The Other' and 'stereotyping'. We argue that the concept of 'online othering' encapsulates the myriad power contestations and abusive behaviours which are manifested on/through online spaces (including for example as racism, islamophobia, sexism, misogyny, homophobia, ableism) and which are resisted and challenged by various social actors and groups. The concept of 'online othering' is a means of analysing and making sense of the myriad behaviours, conversations, and discourses which seek to (re)draw boundaries in, around, and between virtual spaces, and which shape the rules and norms concerning which individuals and groups are endowed with status and legitimated to participate in these spaces, and those who are not. We then outline the synopsis of the edited volume, its contribution and aims, and the focus of each section and its respective chapters.

\section{Online participation, inequalities and the political economy}

The internet plays a vital role in many aspects of our social, political and cultural lives and in the early days of its expansion there was much enthusiasm for its potentially transformative role in providing a space for individuals to construct their identities, communicate with others and share ideas and concerns (Turkle, 1995; Paracharissi, 2002). Early proponents of these arguments were hopeful that the internet could operate as a virtual extension of the public sphere to deliberate on political and social issues. Much more than this, it was celebrated as a potential space where one's identity or background could be circumvented and made irrelevant (van Zoonen, 2002). In her essay, The Virtual Sphere, Zizi Papacharissi (2002) sought to question the ability of the internet to promote rational public debate and enhance social life or whether its revolutionary potential would become absorbed by commercial culture. If we take into account the feminist critique of the concept of a universal public sphere, advanced by 
Pre-print version of: Harmer, E. and Lumsden, K. (2019) 'Introduction: Online Othering.' In: K. Lumsden and E. Harmer (eds) Online Othering: Exploring Violence and Discrimination on the Web. Basingstoke: Palgrave Macmillan.

scholars like Nancy Fraser (1992), it now seems obvious that the virtual sphere is not a neutral space and that it reflects the inequalities that are experienced in the offline world. Fraser's argument that discursive interaction within the public sphere is governed by protocols of style and decorum that are in themselves markers of status which therefore act as informal impediments' to equal participation, is important to consider when discussing the extent to which online participation can be thought of as inclusive (Fraser, 1992: 63).

Inclusive participation can also be disrupted by the political economy of the internet (Fuchs, 2017). Political economy approaches to the analysis of communication industries focus on the relationship between the economic structure and the dynamics of media corporations (McQuail, 2010). Fuch's (2009) suggests that the internet's economic model is built on the commodification of its users whereby free to access platforms essentially deliver users up as targets for advertisers. In relation to social media, he argues that there are huge asymmetries in the visibility of different content providers, and he suggests that this limits ability for social media sites to enable participation. For example, his analysis of the most viewed videos on YouTube indicates that transnational media corporations control what he refers to as the attention economy, whereby the majority of these videos are corporate music videos, meaning that the most viewed content comes from providers who already have other means of distributing their content, whilst smaller providers are squeezed out. He also argues that the digital affordances of platforms impact the quality of participation, for instance micro-blogging sites such as Twitter, where the number of characters in tweets are limited, can lead to simplistic and superficial engagement. It is therefore clear that corporations dominate social media, and the internet's status as a capitalist enterprise means that these platforms exist to accumulate profits rather than to enable equal participation. Despite the potential for digital technology to democratise the communication process, it is clear that pre-existing social, 
Pre-print version of: Harmer, E. and Lumsden, K. (2019) 'Introduction: Online Othering.' In: K. Lumsden and E. Harmer (eds) Online Othering: Exploring Violence and Discrimination on the Web. Basingstoke: Palgrave Macmillan.

political and economic inequalities have intelligible impacts on the ability of people to participate in online cultures, and the manner in which that participation is realised.

\section{Discrimination, harassment and hate online}

It is perhaps unsurprising then that an unintended consequence of digital technology has been the extent to which some individuals and groups have used the freedom to participate online to engage in hateful or discriminatory communicative practices in these loosely regulated spaces, often hiding behind the cloak of anonymity (Papacharissi, 2004). One of the earliest example is \#Gamergate, where online users systematically harassed women game developers, journalists and critics in a form of backlash against women's use of technology and participation in public life (Massanari, 2017). Women in the public eye have found themselves subjected to hate crime on Twitter (Citron, 2016) in the form of online harassment, sexism and trolling. Moreover, the aftermath of the Brexit vote in the United Kingdom saw a rise in reports of hate speech including racism, Islamophobia, and anti-Semitism, in both online and offline contexts (Devine, 2018; Komaromi and Singh, 2016; Awan, 2016). These instances also highlight the intersectional nature of online hate as studies indicate that the majority of victims of online Islamophobia tend to be female (Feldman and Littler, 2014). The reasons given for this include women being more likely to report online abuse, and also in offline cases the greater visibility related to items of clothing (such as the hijab) (Gerard and Whitfield, 2016). The evolution of the internet demonstrates that the affordances of digital media technologies often serve to replicate and perpetuate the social inequalities that people already experience. This is underscored by the work of Safiya Umolja Noble (2018) which shows how pre-existing prejudices about social differences are built in to the very architecture of the internet at source, which ultimately serve to reflect and perpetuate existing inequalities. Her study of the Google search engine reveals that the algorithms used by the company are based upon and perpetuate 
Pre-print version of: Harmer, E. and Lumsden, K. (2019) 'Introduction: Online Othering.' In: K. Lumsden and E. Harmer (eds) Online Othering: Exploring Violence and Discrimination on the Web. Basingstoke: Palgrave Macmillan.

harmful racist and misogynistic stereotypes. Similarly, scholars have demonstrated that the nature of programming languages used to write digital code can be used to express misogyny (Easter, 2018). Moreover, Massanari (2017) argues that the design, culture and policies of platforms such as Reddit encourage certain toxic behaviours which can supress equal participation.

The internet has also been implicated in othering and discrimination in people's everyday domestic lives. Concerns have been expressed over its use in crimes such as identity theft, fraud, buying illicit substances or weapons, stalking, and technology-facilitated domestic abuse (Powell and Henry, 2016; Dragiewicz et al., 2018). The New York Times reported in 2018 that smart home technology and connected home devices which monitor and regulate thermostats, locks and lights are being used as 'digital tools of domestic abuse', and a means for harassment, monitoring, revenge and control (Bowles, 2018). Moreover, various smart phone apps can also be used by perpetrators to stalk and coerce in intimate partner violence. Chatterjee et al. (2018) found that over 200 apps and services offer 'would-be stalkers' a variety of capabilities, including basic location tracking to harvesting texts and secretly recording video. In the design of these technologies it is rarely considered how they could be used to control, coerce and/or stalk, by individuals who have sinister or harmful motives. Digital media have also enabled incidents of cyberbullying and harassment, 'revenge porn' or image-based sexual abuse (McGlynn, Rackley and Houghton, 2017; Smith, this volume) whereby personal images are shared online without the person's consent, and 'Deepfake' pornography where digital images are manipulated to include the faces of people who are not in the original image.

Social scientists have also explored the social media phenomenon referred to as 'trolling' (Phillips, 2015; Binns, 2012; Jane, 2014a 2014b; Herring, 1999, 2003; Hardaker, 2010; 
Pre-print version of: Harmer, E. and Lumsden, K. (2019) 'Introduction: Online Othering.' In: K. Lumsden and E. Harmer (eds) Online Othering: Exploring Violence and Discrimination on the Web. Basingstoke: Palgrave Macmillan.

Hardaker and McGlashan, 2016; Marwick and Ellison, 2012; Lumsden and Morgan, 2017). Trolling can be likened to a form of cyber-bullying and involves the sending or submission of provocative emails, social media posts, or 'tweets' (Twitter messages), with the intention of inciting an angry or upsetting response from its intended target or victim. In contrast to visibility, anonymity has been deemed important for making trolling possible in a variety of online spaces (Hardaker, 2010; Hardaker and McGlashan, 2016; Hutchens et al., 2015) and this form of online bullying is often committed incognito. Trolling attempts to hijack and disrupt normative interactions and communication practices and also to 'oust' the victim from participation in public forums of debate.

Trolling developed from early internet users' 'flaming' of online forms and bulletin boards (Donarth, 1999; Kiesler, Zubrow and Moses, 1985; Lea et al., 1992; Hangwoo, 2005; O'Sullivan and Flanagin, 2003; Hmielowski et al., 2014). The term is now used to refer to abuse or harassment of individuals or groups on social media sites, online comments pages, blogs, and social networking. For Herring et al. (2002: 372): 'Trolling ... differs from flaming in that the goal of flame bait is to incite any and all readers, whereas the goal of a stereotypical troll is to draw in particularly naive or vulnerable readers'. In her study of self-identifying 'subcultural trolls' in the USA, Phillips highlights trolling's relationship to the wider media cultural landscape. For instance, trolls can engage in 'media fuckery', which is the 'ability to turn the media against itself' (2015: 2). This is accomplished by amplifying or inventing a sensational news story, i.e. 'fake news'. In this sense:

Trolls ... fit very comfortably within the contemporary, hypernetworked digital media landscape. Not only do they put Internet technologies to expert and highly creative use, their behaviours are often in direct (if surprising) alignment with social media marketers 
Pre-print version of: Harmer, E. and Lumsden, K. (2019) 'Introduction: Online Othering.' In: K. Lumsden and E. Harmer (eds) Online Othering: Exploring Violence and Discrimination on the Web. Basingstoke: Palgrave Macmillan.

and other corporate interests ... In short, rather than functioning as a counterpoint to 'correct' online behavior, trolls are in many ways the grimacing poster child for the socially networked world. (Phillips, 2015: 8)

Prominent forms of abuse targeted at women online which are often part of trolling behaviour/s include rape threats and death threats. 'Rape culture' can be seen to have re-emerged within popular discourses over the past five years and is 'a socio-cultural context in which an aggressive male sexuality is eroticized and seen as a "healthy", "normal", and "desired" part of sexual relations' (Keller et al., 2015: 5; Herman, 1978). Jane (2014a: 535) notes that this discourse has become normalized to the extent that 'threatening rape has become the modus operandi for those wishing to critique female commentators'. Mantilla (2015) identifies 'gendertrolling' as distinct from forms of trolling which more generally attempt to disrupt or hijack online interactions. 'Gendertrolls' have a different motivation and 'gendertrolling is exponentially more vicious, virulent, aggressive, threatening, pervasive, and enduring than generic trolling ... gendertrolls take their cause seriously, so they are therefore able to rally others who share in their convictions ... [and] are devoted to targeting the designated person' (Mantilla, 2015: 11). New forms of media can also exacerbate issues surrounding sexual violence by creating digital spaces wherein the perpetration and legitimization of sexual violence takes on new qualities (Dodge, 2015). Moreover, online abuse both redeploys existing manifestations of rape culture and intensifies them due to the speed at which images and written communications can be shared online (Shariff and DeMartini, 2015).

As Lumsden and Morgan (2017) note, trolling can cross the boundary from an exchange of teasing remarks or humour, to sustained abuse by one or more individuals, and which can be viewed as a form of gendered and/or 'symbolic violence' or a 'silencing strategy'. Advice to 
Pre-print version of: Harmer, E. and Lumsden, K. (2019) 'Introduction: Online Othering.' In: K. Lumsden and E. Harmer (eds) Online Othering: Exploring Violence and Discrimination on the Web. Basingstoke: Palgrave Macmillan.

victims on how to respond to trolling includes such statements as: 'do not feed the troll' (Binns, 2012) and 'ignore the troll'. The implication implicit in this advice for dealing with trolls is that victims should be silenced. This is particularly a problem in relation to women, who have become particularly susceptible to online gendered and symbolic violence by cyber-trolls and who are being advised, implicitly or explicitly, to 'put up and shut up', reminiscent of advice given concerning how best to respond to gendered violence and sexism in the past (Lumsden and Morgan, 2017).

The term trolling is also problematic in that it is now widely utilised by the media and others to also describe the posting of offensive messages per se by an individual in addition to the more proactive, deliberate and organised hate campaigns engaged in by groups of individuals, in a pre-meditated manner. As Hardaker argues trolling has become a 'catch-all term for any number of negatively marked online behaviours' (2010: 224) which is why there is a need to reconceptualise how we understand abusive and hateful behaviours online, as we do in this edited collection via the concept of 'online othering' (and which will be outlined in more detail below). As well as being used to describe the above, trolling is drawn on to describe individual messages posted online which are deemed by the recipient and/or audience to be defamatory or abusive. Hence, with these instances of trolling, the question of intent is important in the creation of the communication, as is the interpretation of the message by the recipient and wider audience - as 'in the eyes of the beholder'. These above analyses of online abuse also highlight the tension between 'libertarian and communitarian values, in that harassment often arises in spaces known for their freedom, lack of censure, and experimental nature' (Herring et al., 2002: 374; Herring, 1999). For these reasons, trolling as a catch-all term is problematic in that it does not acknowledge the implications and impact of online abuse and toxic interactions on individuals and groups in the way that our concept of 'online othering' permits. 
Pre-print version of: Harmer, E. and Lumsden, K. (2019) 'Introduction: Online Othering.' In: K. Lumsden and E. Harmer (eds) Online Othering: Exploring Violence and Discrimination on the Web. Basingstoke: Palgrave Macmillan.

\section{A threat to democracy? The rise of the Alt-Right and Trumpism}

The contemporary political landscape also gives us pause for thought. In contrast to the early optimism about the use of digital technologies for the advancement of democracy, recent events have instead seen some disturbing trends which, rather than enhancing democratic deliberation, have in fact come to threaten democracy itself. The rise of neo-fascist politics in online spaces characterised as the so-called 'Alt-Right' has been the focus of much attention (Hawley, 2017; see also Winter, Green, and Lumsden, this volume), in addition to the rise in various forms of hate speech such as misogyny, racism and Islamophobia (Citron, 2016; Awan, 2016). The 'AltRight' is a political movement which came to prominence in the wake of the 2016 US Presidential Election. According to Squirrell (2017a) anecdotal evidence largely suggests that the movement incorporates individuals from the 'manosphere', anti-progressives from the \#GamerGate movement, 4chan trolls, far-right conservatives, racists, and conspiracy theorists. There have also been concerns about the ways in which social media in particular have endangered the political process itself, including the rise of 'Trumpism' online (Bessire and Bond, 2017; Squirrell, 2017b). Rumours abound about the alleged interference in the US presidential election and the EU Referendum in the UK by foreign powers, and the potential impact of so-called 'fake news' coming from Russian and Eastern European Troll farms, which platforms like Facebook and Twitter have struggled to challenge.

We have already seen that the economic imperatives and design of most mainstream internet platforms have implications for the reproduction of existing social inequalities, but this is further exacerbated by the reticence on the part of these platforms to regulate themselves in any way, citing concerns about the chilling effect on freedom of speech and expression which are therefore easily exploited by those who wish to continue using cyberspace as a vehicle for 
Pre-print version of: Harmer, E. and Lumsden, K. (2019) 'Introduction: Online Othering.' In: K. Lumsden and E. Harmer (eds) Online Othering: Exploring Violence and Discrimination on the Web. Basingstoke: Palgrave Macmillan.

engaging in online othering and discrimination. Police and criminal justice agencies report difficulties in keeping up with the rise in the numbers of reports of online crime and abuse, while there are currently ineffective means of legislating against and/or investigating and prosecuting cases (Bishop, 2013). Social media corporations, such as Twitter, have been called to task for their slow responses to dealing with online abuse. In 2015 the Chief Executive Officer of Twitter, Dick Costolo, was quoted as stating in a leaked memo: 'We lose core user after core user by not addressing simple trolling issues that they face everyday ... I'm frankly ashamed of how poorly we've dealt with this issue during my tenure as CEO. It's absurd' (Griffin, 2015).

Facebook for example has been variously criticised for failing to ban groups engaging in the sharing of sexual images of children (Crawford, 2017). Twitter proved to be reluctant to moderate content at all, only adding an 'in-tweet' reporting function for inappropriate or hateful content in 2013 after pressure from users who had experienced harassment and threats of violence. Platforms have also been accused of discrimination. YouTube faced a backlash from some of its LGBTQ content creators for allegedly filtering out videos about same-sex marriage and trans issues (Cuthbertson, 2018). Twitter has also been urged by disability charities to do more to help disabled users report hate speech against them on the site, with claims that it remains too difficult to report disability-related abuse. According to Muscular Dystrophy UK, the lack of a clear option to label abusive tweets based on disability is preventing more reporting of such hate speech (ITV News, 2018). In addition to demonstrating an unwillingness to moderate content, there have been a number of incidents which show the complexities of moderating platforms with a global reach. For example, Facebook has faced intense criticism for failing to curb anti-Rohingya propaganda in Burma at a time where state-sponsored violence has already been used to devastating effect against this minority Muslim community. 
Pre-print version of: Harmer, E. and Lumsden, K. (2019) 'Introduction: Online Othering.' In: K. Lumsden and E. Harmer (eds) Online Othering: Exploring Violence and Discrimination on the Web. Basingstoke: Palgrave Macmillan.

Facebook has blamed a lack of moderators with the right language skills for its difficulties (see Rajopalan et al., 2018). It is clear that the scale of the problem facing these technology corporations is proving impossible to respond to and regulate effectively. There have been some positive moves though. As discussed previously, Twitter introduced a report function and Facebook have made some efforts to moderate hate speech and hate groups but there is clearly a long way to go.

\section{Political organisation, activism, and resistance to 'online othering'}

Despite the seemingly overwhelming examples where online sites and technologies reinforce and perpetuate social inequalities and contribute to the further exclusion of already marginalised groups and individuals, it is important to remember that the advent of such digital technologies offer significant opportunities for resistance and political organisation in order to counter some of the unfortunate consequences of online othering. Feminist groups have demonstrated a sustained commitment to organising online despite its many challenges (see for example Keller et al., 2016; Williams, 2015). There has been a proliferation of activism, online blogs, groups and press reports, which highlight the trolling and abuse experienced by women online. As Korn and Kneese (2015: 208) note, feminist scholars have demonstrated the ways in which 'online interactions over particular social media platforms coincide with existing inequalities and hierarchies situated in specific communities', and also the ways in which feminists, as counter-publics, can garner support and attention via social media. Specific blogs and platforms have also been created in order to share experiences and raise awareness of feminist causes such as the Everyday Sexism project, founded in the UK but which now has sites in many different languages which allow women to share experiences of sexism or harassment online (Bates, 2014). The proliferation of social media hashtags designed to challenge social and political inequalities is another example. The \#MeToo movement calling 
Pre-print version of: Harmer, E. and Lumsden, K. (2019) 'Introduction: Online Othering.' In: K. Lumsden and E. Harmer (eds) Online Othering: Exploring Violence and Discrimination on the Web. Basingstoke: Palgrave Macmillan.

out sexual misconduct in media industries and the \#Blacklivesmatter matter movement began as online campaigns (Tynes et al., 2016) demonstrating the potential for digital technologies to be used to effectively challenge the status quo.

Keller, Mendes and Ringrose (2015) focus on the ways in which girls and women use digital media platforms to challenge the rape culture, sexism and misogyny they experience in everyday life. A special issue of Feminist Media Studies (2015) also highlights the use of feminist hashtags to expose the transnational pervasiveness of gendered violence, to create a space for women to share their experiences and, therefore to challenge commonsense understandings of abuse and promote solidarity (Berridge and Portwood-Stacer, 2015). Examples include black feminists' use of social media to fill the gap in national media coverage of black women's issues, including how race and gender 'affect the wage gap to the disproportionate amount of violence committed against black transgender women' (Williams, 2015: 343). Khoja-Moolji (2015) highlights the use of 'hashtagging' as a form of activism which is encouraged by campaigns for girls' empowerment, while Eagle (2015) focuses on their use as part of a campaign to improve women's use of transport and public space, without the fear of sexual harassment. In addition, research by Parker and Song (2006) on young South Asian and Chinese communities in Britain's use of websites demonstrates that internet discussion forums can act as witnesses to social inequalities and through sharing experiences of racism and marginalisation, an oppositional social perspective may also develop. They demonstrate how the campaigns stimulated by users of these websites challenged mainstream institutions and began to alter the terms of engagement between the ethnic groups and wider society. 
Pre-print version of: Harmer, E. and Lumsden, K. (2019) 'Introduction: Online Othering.' In: K. Lumsden and E. Harmer (eds) Online Othering: Exploring Violence and Discrimination on the Web. Basingstoke: Palgrave Macmillan.

However, Berridge and Portwood-Stacer (2015: 341) highlight the dangers that feminists can encounter in relation to threats of gendered violence that occur within online spaces. For women accessing the public space of the internet, there is a double-edged sword in that it promotes freedom of expression and provides a space for feminist activism, while it also presents the risk of a backlash from potential trolls, as a means of curtailing women's appropriation of, and participation in, online spaces. As Keller, Mendes and Ringrose (2015: 5) note, 'anyone who challenges popular misogyny puts themselves at risk of becoming the subject of sexist attacks and abuse'.

Many of the above studies focus more specifically on the experiences of feminist scholars and feminist activists already in the public eye (and with an online presence). In addition to this work, we also need increased social scientific analysis of the everyday experiences of women (and men) utilising various forms of online and digital communications, which this edited collection addresses. For example, in a study by Sills et al. in which they interviewed young people about their exposure and responses to 'rape culture' on social media, their participants conveyed a sense of 'living within a matrix of sexism: that is, an environment in which sexism, misogyny, and elements of rape culture merge as a normalized backdrop to everyday life' (2016: 6). These behaviours then, are becoming normalized on-and-offline and for these young people 'victim-shaming' and 'slut-shaming' were viewed as commonplace and everyday.

In the context of this rapidly changing and politically contested social media landscape, this edited collection explores the othering and discrimination propagated and encountered by individuals online and in social media contexts and cultures. It problematizes and analyses the dichotomy presented between real and virtual worlds (and spaces) by exploring the motivations behind certain offending and othering behaviours, and the impact this has on the targets of 
Pre-print version of: Harmer, E. and Lumsden, K. (2019) 'Introduction: Online Othering.' In: K. Lumsden and E. Harmer (eds) Online Othering: Exploring Violence and Discrimination on the Web. Basingstoke: Palgrave Macmillan.

online abuse and hate speech. This includes the extent to which 'online othering' constitutes a new phenomenon and how the motivations for committing forms of cyber-abuse, cyber-hate, and othering relate to the expression of these attitudes and behaviours in the offline context. It explores the extent to which forms of information and communication technologies facilitate, exacerbate, and/or promote the enactment of traditional offline offences (such as domestic abuse and stalking). Finally, the collection addresses the role of the police and other agencies in terms of their interventions, and the regulation and governance of virtual space(s).

The edited collection takes an interdisciplinary approach to these phenomena. Contributors come from a variety of disciplines including sociology, communication and media studies, psychology, criminology, political studies, information science, and gender studies. Contributions address the ways in which various groups and identities are subjected to othering in online environments, and those groups and cultures doing the othering. This includes examples from a variety of online media and mediums including news websites, social media platforms (i.e. Twitter, Facebook, Instagram, YouTube.), blogs, and forums such as Reddit and 4/Chan. Some contributions explore othering across multiple contexts. In addition, chapters cover historical and theoretical perspectives on 'online othering', and empirical research using a variety of methods. Contributions also consider the implications for the regulation of the internet by police and prosecutors, policy and practice. Topics covered in the book include: trolling and gendered online abuse/harassment; sexting and revenge porn; the rise of the AltRight and Trumpism; Men's Rights Activists; cyber-stalking; online racism; transphobia; and the policing and prosecution of online hate crime.

\section{'Online othering', agency and resistance}

'if there were no other, one would invent it.' (Cixous and Clement, 1975: 71) 
Pre-print version of: Harmer, E. and Lumsden, K. (2019) 'Introduction: Online Othering.' In: K. Lumsden and E. Harmer (eds) Online Othering: Exploring Violence and Discrimination on the Web. Basingstoke: Palgrave Macmillan.

In this volume we develop and propose the concept of 'online othering' as a means of describing and making sense of the myriad behaviours, interactions and discourses which seek to (re)draw boundaries in, around, and between virtual spaces, and shape the rules and norms concerning which individuals and groups are endowed with status and legitimated to participate in these spaces, and those who are not. Furthermore, we recognise the various strategies and responses to experiences of 'online othering' thus ensuring that the agency of 'others' and means of resisting and responding to prejudice and discrimination online (i.e. via activism), are accounted for. The concept of 'online othering' also allows us to examine the justifications and motivations of those who perpetrate or enact online discrimination, prejudice, hate and/or abuse, ultimately 'othering' those who are deemed to be 'them', 'outsiders', or members of the 'out-group'. 'Online othering' can be done remotely, 'at a distance', with little regard to the real-world consequences and harms which are experienced by those who are 'othered' in online spaces.

As noted above, thus far understandings of online hate and/or cyber-deviance have focused on specific phenomena such as 'abuse', 'harassment', 'trolling', 'hate speech' or 'hate crime'. We do not wish to minimise the real harm and implications which these phenomena and behaviours have for victims and/or survivors. However, we argue that currently these terms alone do not adequately help us to understand and conceptualise how exclusion from the internet and its spaces operates across various groups, individuals and contexts. Many forms of abuse are not recognised as 'harmful' or are not incorporated as 'hate crime' in laws and legislation, and what is defined as hate speech (or even if it can be deemed to 'hate speech' given the online versus offline nature) also varies across countries and continents. For example, recent developments in the United Kingdom have included a proposal in 2018 to classify misogyny 
Pre-print version of: Harmer, E. and Lumsden, K. (2019) 'Introduction: Online Othering.' In: K. Lumsden and E. Harmer (eds) Online Othering: Exploring Violence and Discrimination on the Web. Basingstoke: Palgrave Macmillan.

as a 'hate crime', and proposals to classify 'upskirting' (which involves taking a photograph under a victim's skirt) as a crime.

Moreover, despite the inclusion of the term 'online', we, like others, believe it is important to acknowledge that these behaviours do not occur in a 'virtual vacuum' - they are part and parcel of everyday life, and have real consequences in what some have chosen to call the 'real' (versus the 'virtual') world. We must throw out the well-worn dichotomies of 'online versus offline', and 'virtual world' versus 'real world', and instead acknowledge the interconnected and fluid nature of our everyday use of information and communication technologies (see also Lumsden and Morgan, 2017; Papacharissi, 2016).

The practices and processes through which the 'outsider' is constructed is encapsulated via the notion of 'othering'. According to Lister, othering is a 'process of differentiation and demarcation, by which the line is drawn between "us" and "them" - between the more and the less powerful - and through which social distance is established and maintained' (2004: 101) It involves constructions of the self or 'in-group', and the other or 'out-group', through identification of what the former has and what the latter lacks in relation to the former (Brons, 2015: 70). It is the means of defining into existence a group perceived to be 'inferior' (Schwalbe et al., 2000: 422). Jensen (2011) traces the establishment of the concept of 'othering' through Hegel, de Beauvoir, Said, Lacan, Althusser, and Spivak, to its current general usage to signify 'classed', 'raced' and 'gendered' processes through which powerful groups simultaneously claim a monopoly on crucial knowledge and technologies, use ways of actively demonstrating their power and construct/exclude less powerful others as pathological, 'dangerous' and/or morally inferior. For the psychoanalyst Jacques Lacan (1977), the discourse of the 'other' is the unconscious mind of the subject. According to Lacan infants develop a 
Pre-print version of: Harmer, E. and Lumsden, K. (2019) 'Introduction: Online Othering.' In: K. Lumsden and E. Harmer (eds) Online Othering: Exploring Violence and Discrimination on the Web. Basingstoke: Palgrave Macmillan.

sense of self during the 'looking-glass-phase' through differentiating their self from Others. This results in the construction of a 'self for others', always 'referential to the other' (Segal, 1994: 131). Therefore, as Wilkinson and Kitzinger argue it is important that as scholars and researchers we always remember that 'we' use the 'other' to define ourselves: "we" understand ourselves in relation to what "we" are not' (1996: 8).

The concept of 'othering' also attempts to capture the practices and processes through which the 'outsider' is produced. For Bauman, identities are set up as dichotomies:

In dichotomies crucial for the practice and vision of social order the differentiating power hides as a rule behind one of the members of the opposition. The second member is but the other of the first, the opposite (degraded, suppressed, exiled) side of the first and its creation. Thus abnormality is the other of the norm ... woman the other of man, stranger the other of the native, enemy the other of friend, 'them' the other of 'us'. (1991: 14; see also Gingrich, 2004)

By defining itself against an 'other', the dominant group silences or delegitimizes the 'other' (Wilkinson and Kitzenger, 1996). Moreover, 'others" representations of themselves or the dominant group are viewed as a threat by dominant groups (Sampson, 1993). As Stuart Hall (1997) notes, representation through language is central to the processes by which meaning is produced, and visual representations of 'otherness' hold cultural authority. Hall's work, including his writings on race and racism, can be characterized as encompassing 'the desire to contest, to pry open, essentialized claims of national identity ... to find a space for the "others" in the national imaginary' (Alexander, 2009: 464; i.e. see Hall, 2000). Therefore, dominant or hegemonic groups can exert control over processes of representation while representations of 
Pre-print version of: Harmer, E. and Lumsden, K. (2019) 'Introduction: Online Othering.' In: K. Lumsden and E. Harmer (eds) Online Othering: Exploring Violence and Discrimination on the Web. Basingstoke: Palgrave Macmillan.

otherness can also be read as inverted representation of those doing the othering (i.e. see early ethnographies of non-Western cultures) (Wilkinson and Kitzinger, 1996; hooks, 1990).

Early work on 'othering' focused on woman as 'other', mainly drawing on Simone de Beauvoir's seminal work The Second Sex, in which she appropriates Hegel's concept of 'the Other' to demonstrate that:

[Woman] is defined and differentiated with reference to man and not he with reference to her; she is the incidental, the inessential as opposed to the essential. He is the Subject, he is the Absolute - she is the Other. (1949: 16)

De Beauvoir's notion of 'the Other' was heavily influenced by Hegel's dialectic of identification and distantiation in the encounter of the self with an 'other' as written in his 'Master-Slave Dialectic' (1807 B.IV.A cited in Brons, 2015: 69). The concept of woman as 'Other' more often than not involves the central claim that: '... Otherness is projected onto woman by, and in the interests of, men, such that we are constructed as inferior or abnormal' (Wilkinson and Kitzinger, 1996: 4). Above all, it is women's sexual bodies which are the focal point for othering, an othering which has become ever more sophisticated as a result of the masculine institution of medicine and masculine modes of knowledge (Jackson et al., 1993). Ussher argues that the oppression of 'mad women' can be seen as a form of 'misogynistic torture' whereby 'misogyny makes women mad either through naming us as "the Other", through reinforcing the phallocentric discourse, or through depriving women of power, privilege and independence' (1992: 7). However, women do not have a monopoly to 'otherness' (Wilkinson and Kitzinger, 1996) as Simone de Beauvoir herself highlighted in her reference to what she termed 'other Others': 
Pre-print version of: Harmer, E. and Lumsden, K. (2019) 'Introduction: Online Othering.' In: K. Lumsden and E. Harmer (eds) Online Othering: Exploring Violence and Discrimination on the Web. Basingstoke: Palgrave Macmillan.

No group ever sets itself up as the One without at once setting up the Other over against itself ... [T] o the native of a country all who inhabit other countries are 'foreigners'; Jews are 'different' for the anti-Semite, Negroes are 'inferior' for American racists, aborigines are 'natives' for colonists, proletarians are the 'lower class' for the privileged. (1949: 52)

Black feminist scholars have recognised the intersectional aspects of 'othering' in relation to the oppression of woman of colour and non-Western people (i.e. see Hill Collins, 1990; Patai, 1991; Fine, 1994). These works recognise that "representations of women which "imply" a homogenous category of Otherness render invisible the different experiences of women of varied ethnic, sexual and class locations' (Wilkinson and Kitzinger, 1996: 5). Patricia Hill Collins (1990) discusses what she calls 'marginal outsiders' and the notion of 'othering' is incorporated as part of her 'matrix of domination'; a paradigm which explains the overall organisation of power within society and which has a particular arrangement of intersecting systems of oppression. The systems come together in a manner which is historically and socially specific. They are also organized via four interrelated domains of power: structural, disciplinary, hegemonic, and interpersonal. Patricia Hill Collins (1991[1986]) outlines a black feminist standpoint and draws attention to women's marginal status which she refers to as an 'outsider within status'. For Collins, intersectionality is key as diversity of experiences will be reflected in and shaped by other aspects of identity including class, religion, age and sexuality (see also Crenshaw, 1989). Therefore, acknowledging that intersectionality is part of 'othering' further permits us to account for how social categories are positioned in such a way as to distinguish 'insiders from outsiders' (Collins, 1998: 69). 
Pre-print version of: Harmer, E. and Lumsden, K. (2019) 'Introduction: Online Othering.' In: K. Lumsden and E. Harmer (eds) Online Othering: Exploring Violence and Discrimination on the Web. Basingstoke: Palgrave Macmillan.

Othering is also evident in the construction and representation of discourses of the oppressed, which act to justify the oppressor, as noted in Edward Said's (1978) anthropological critique of orientalism. Said's work is concerned with the scholarly disciplines and ideological and imaginative representations by which the West has constructed and come to know the nonWestern world as 'Other'. According to Said, Europe constructed a discourse of 'Otherness' in order to come to terms with colonies in the Orient. This involved the recreation of their history of people 'outside of it', justifying colonial rule and explaining the fall of Oriental cultures. For example, in relation to India, Said notes that: 'The bulk of colonial writing in India focused on demonstrating the peculiarities of Hindu civilisation, and the barbaric practices pertaining to women' (1978: 34). The representation of these civilisations as 'Other' thus operates to reinforce the power and superiority of those with control over processes of representation (Wilkinson and Kitzenger, 1996). Thus, in addition to gender, 'othering' has also been used to theorize race, ethnicity and colonialism (Wilkinson and Kitzenger, 1996).

Stereotypes are one aspect of 'othering'. Michael Pickering (2001) argues that stereotypes are a system of categorization which installs order. They represent cultural processes, practices and understandings which create meaning. Stereotypes are endowed with ideological views and values and 'create a sense of order through the negation of broader or expansive understandings, foreclosing many of the issues relating to the difference and diversity of a subject matter before these same issues can be subsequently put forward, made known or engaged with' (Allen, 2010: 143). Stereotypes construct 'difference as deviant for the sake of normative gain' (Pickering, 2001: 7), and operate by creating boundaries and fixing meaning as to what is positive or negative, normal or deviant/alien/'Other'. Pickering (2001) claims that a historical understanding of stereotypes can assist in making evident how stereotypes often 
Pre-print version of: Harmer, E. and Lumsden, K. (2019) 'Introduction: Online Othering.' In: K. Lumsden and E. Harmer (eds) Online Othering: Exploring Violence and Discrimination on the Web. Basingstoke: Palgrave Macmillan.

draw on long-standing images of particular groups which have remained largely dormant. For Pickering (2001: 48):

Stereotyping is ... a way of warding off any threat or disruption to 'us' as the 'same together' through the generation of the essentialized Otherness ... It is a collective process of judgement which feeds upon and re-enforces powerful social myths.

Therefore, stereotypical traits are used to reinforce the notion of otherness. Stereotyping involves a heightened focus on the other (as 'different') and a disavowal or distancing of those who are 'Othered' (see also Hall, 1997). For Essed (1991), othering also involves people opting out of seeing or responding to discrimination such as racism.

The concept of 'othering' is not without its critics. For example, it has been criticised for denying agency to those who are 'othered' (Bhatt, 2006). Jensen (2011) argues that the binary nature of 'othering' sets up a frame of reference which fails to see the in-between, the 'thirdspace' (Soja, 1996), and which, in the context of the differentiation referred to earlier in relation to people, temporalities, geographical locations and social spaces, denies active agency to a supposedly unified 'voiceless subaltern' (Jensen, 2011: 101). In the Location of Culture, Bhabha's (1994; see also Soja, 1996) theory of cultural difference provides us with the conceptual vocabulary of 'hybridity' and the 'third space'. He develops Turner's concept of liminality to propose the concept of third space as a position from which new identities and potentialities emerge. 'Third space' is critical of essentialist positions of identity and of 'originary culture' (Bhabra, 1994). Third space contains new possibilities. It is a space in which cultural meaning and representation have no 'primordial unity or fixity' (Bhabha, 1994). 
Pre-print version of: Harmer, E. and Lumsden, K. (2019) 'Introduction: Online Othering.' In: K. Lumsden and E. Harmer (eds) Online Othering: Exploring Violence and Discrimination on the Web. Basingstoke: Palgrave Macmillan.

Other writers have, with explicit reference to Spivak's (1985) use of Jacques Lacan, spoken of othering as 'psychoanalytical fatalism in critical disguise' (Gingrich, 2004: 11). Spivak (1985) coined the theoretical concept of othering in her essay on 'The Rani or Sirmur' in which she discusses three dimensions of othering in archival material of British colonial power in India. These three dimensions include: the operation of power in terms of producing the other as subordinate; constructing the other as pathological and morally inferior; and the implication that knowledge and technology are the property of a 'powerful, empirical self, not the colonial other' (Jensen, 2011: 65). Spivak's notion of othering has much in common with the concept of intersectionality (Crenshaw, 1991) and 'interlocking systems of oppression’ (Collins, 1989) discussed above, since it is multidimensional and deals with several forms of social differentiation (Jensen, 2011). Therefore, in Spivak's work:

... othering concerns the consequences of racism, sexism, class (or a combination hereof) in terms of symbolic degradation as well as the processes of identity formation related to this degradation. (Jensen, 2011: 65)

Jensen (2011) addresses objections to the concept of othering by building on McLaren's (1994) notion of 'oppositional agency'. From McLaren's perspective, the conservative/liberal stress on sameness and the left-liberal emphasis on difference form a false opposition. Sameness and difference should not be seen as essentialist categories: rather, 'difference is always a product of history, culture, power, and ideology. Differences occur between and among groups and must be understood in terms of the specificity of their production' (McLaren, 1995: 126). In his study of young ethnic minority men in Denmark, Jensen restores agency to the othered through strategies such as: 'capitalization' (appropriating elements of othering discourses in an attempt to imbue the category with symbolic value) and 'refusal' (articulating distance from 
Pre-print version of: Harmer, E. and Lumsden, K. (2019) 'Introduction: Online Othering.' In: K. Lumsden and E. Harmer (eds) Online Othering: Exploring Violence and Discrimination on the Web. Basingstoke: Palgrave Macmillan.

the category by 'talking back' to the othering gaze). Jensen's interviewees attempted to carve out a third space which was 'not defined by firstness and otherness, but transcends the dichotomy: simply as a normal human being - not Danish, but also not different from the Danish' (2011: 74).

People have resisted or challenged 'online othering' through various strategies such as: the reporting of abuse; campaigning for more effective reporting systems on social media platforms; campaigning against online hate and sexual harassment; feminist activism; social media hashtags designed to challenge social and political inequalities. Prominent examples of effective hashtags include the \#MeToo movement calling out sexual misconduct in media industries and the \#Blacklivesmatter matter movement. Various internet sites have also been set up which focus on advice to resist and challenge online hate and trolls. Internet users have also publicly called out the abusive behaviour/s of internet trolls or attempted to open up dialogue with them. For example, the Cambridge classicist scholar Professor Mary Beard adopted the strategy of publicly 'naming and shaming' her trolls (Ellis-Petersen, 2014). Other popular anecdotal advice on how to effectively respond to trolls has included the now wellknown adage: 'do not feed the troll'. However, as discussed above, writers have noted how this strategy can further silence the voices of particular individuals/groups in online spaces (Lumsden and Morgan, 2017).

By introducing the concept of 'online othering', examples of which are provided and analysed in this edited volume, we aim to also address the above criticisms of 'othering'. Our concept of 'online othering' can be summarised as: 
Pre-print version of: Harmer, E. and Lumsden, K. (2019) 'Introduction: Online Othering.' In: K. Lumsden and E. Harmer (eds) Online Othering: Exploring Violence and Discrimination on the Web. Basingstoke: Palgrave Macmillan.

- Providing readers with a conceptual tool through which to analyse and make sense of the myriad toxic and harmful behaviours which are being created through, or perpetuated by, information and communication technologies including the spaces of the internet, social media platforms, smartphone apps, and other inter-connected technologies such as smart home technologies (i.e. 'the internet of things').

- Moving beyond the inflexible and often politically loaded ways of categorising examples of harmful behaviours online referred to in varying contexts as 'abuse','harassment', 'hate', 'hate speech', 'hate crime' and/or 'trolling'.

- Acknowledging the seriousness of certain aspects of 'online othering' and its repercussions. Online abusive communications and behaviours may not always be taken seriously by social media corporations and/or the authorities, but the effects are nonetheless real in terms of the everyday impact on those individuals who are on the receiving end. As Billig (2001) writes in relation to prejudice, not all prejudice and stereotyping are equivalent, and the same can be said for instances of 'online othering'. He argues that:

Even if it is conceded that prejudice is inevitable and that human thinking about social groups involves some or other form of stereotyping, then this does not mean that all prejudices and all stereotyping are equivalent. Indeed, the term 'prejudice' may be too anodyne to cover all forms of intergroup stereotyping. Stereotypes, even if they are broadly 'negative', can be distinguished in terms of their intensity and ideological importance. (Billig, 2001: 177)

- Addressing the role of power and privilege at various levels including in the design of information-communication technologies (largely by those in privileged positions (read: white, middle-class men)), and without consideration of unanticipated 
Pre-print version of: Harmer, E. and Lumsden, K. (2019) 'Introduction: Online Othering.' In: K. Lumsden and E. Harmer (eds) Online Othering: Exploring Violence and Discrimination on the Web. Basingstoke: Palgrave Macmillan.

(potentially harmful) consequences and the ways in which technologies can be used for purposes not initially considered or planned in their design (i.e. the use of smartphone apps for stalking and coercion).

- Acknowledging how 'online othering' entails intersectionality with social characteristics and locations such as class, gender, age, race, ethnicity, religion, nationality, disability, sexuality, etc., thus conceptualising across/between/betwixt these, in varying contexts on-and-off-line.

- Incorporating responses to 'online othering' which recognise its oppositional nature and acknowledge the agency of the othered and how resistance to othering can empower and challenge. Thus we draw on the concepts of 'thirdspace' and 'liminality' to recognise that the internet, social media, and how individuals use these, also result in the emergence of new identities and potentialities. We move beyond essentialist positions of identity and of 'originary culture' (Bhabra, 1994).

- Challenging the outdated offline (real) versus online (virtual) dichotomy. Despite our use of the term 'online', we, like others, believe it is important to acknowledge that these behaviours do not occur in a 'virtual vacuum' - they are part and parcel of everyday life, and have real consequences in what some have chosen to call the 'real' (versus the 'virtual') world. We must discard the well-worn dichotomies of 'online versus offline', and 'virtual world' versus 'real world', and instead acknowledge the interconnected and fluid nature of our use of ICTs.

- Acknowledging that when 'interrupting' otherness as scholars and/or researchers we must think about our own and others' 'otherness' without viewing these as essential, fixed attributes. Drawing on the work of Linda Alcoff (1991) who highlights 'the problem of speaking for others', we acknowledge that we must also enquire as to why 
Pre-print version of: Harmer, E. and Lumsden, K. (2019) 'Introduction: Online Othering.' In: K. Lumsden and E. Harmer (eds) Online Othering: Exploring Violence and Discrimination on the Web. Basingstoke: Palgrave Macmillan.

we have an impulse to speak for others. If we decide to proceed we must make explicit how our autobiographies impact on what we say, be open to criticism, and must also acknowledge the effects of speaking on the wider social, cultural, political, discursive and material context(s). This entails a reflexive sensibility which is mindful of those individuals or groups whom we seek to 'speak for' or 'speak of' (see also Lumsden, 2019).

\section{Synopsis of book and overview of chapters}

The overall aim of Online Othering is to contribute to and advance social scientific understandings of the 'othering', discrimination and abuse which occurs in/on/via online spaces, the role of information and communication technologies (and particularly digital and social media) in making possible, facilitating and/or exacerbating 'online othering'. The edited collection explores both experiences of online victimization and othering, and the activist response to online abuse. It further aims to explore the related policing and regulation of online and social media spaces. We explore these themes through the presentation of diverse international case studies from both academics and practitioners. Moreover, the relationships between various macro factors and socio-political institutions and experiences of hate or othering online are explored.

The book is organised into four sections which reflect the overall aims of this edited collection: to understand 'online othering' within the wider social, political, cultural and historical context; to explore the perpetrators of online hate and abuse; to provide an insight into individual and group experiences of 'online othering' including intersections of othering via for example gender, race, ethnicity, sex and sexuality, and disability; to analyse how groups resist 'online othering'; and how the authorities respond to and regulate online abuse and hate. Section I 
Pre-print version of: Harmer, E. and Lumsden, K. (2019) 'Introduction: Online Othering.' In: K. Lumsden and E. Harmer (eds) Online Othering: Exploring Violence and Discrimination on the Web. Basingstoke: Palgrave Macmillan.

brings together three chapters tackling the rise of political extremism online in the guise of the Alt-Right and Men's Rights Activists. The contributions in this section focus in particular on how these groups make use of the digital environment to recruit followers and perpetuate online hatred. This section is also concerned by the ways in which political extremism is gendered and therefore the chapters also address the ways in which masculinity is policed by within extremist contexts online in such a way that it allows misogyny, racism and other forms of prejudice to flourish. Aaron Winter examines the history of the American far-right's use of the internet by analysing how this history developed in response to political changes and emerging technologies; how the adoption of digital technologies changed the status of such movements and their brand of hate and analyses the relationship between their online activity and traditional forms of communication. Alex Green follows by offering an account of the ways in which far-right online communities uphold and police themselves by actively othering dissenters through intersectional categories of gender, racial and sexual deviance. Green argues that straight white men are placed as intellectually, morally and racially superior, and analyses a particular case of when these discourses become unstable when 'insiders' express political opposition. This is seen through strategies of policing that wield homophobia and hegemonic masculinity against dissidents. The final chapter in the section by Karen Lumsden focuses on Men's Rights Activists' (MRA) discussions of trolling and gendered violence on Reddit. Her analysis shows that this group routinely engage in the online othering of 'outsiders', including denigrating and abusing feminists and so-called social-justice warriors. Lumsden shows how MRAs deny that women and feminists are victims of online violence; and instead suggest that it is largely men who are victimised in online spaces.

Section II then foregrounds the extent to which online othering often has a gendered dimension. This section includes accounts of the lived experiences of those who have been subjected to 
Pre-print version of: Harmer, E. and Lumsden, K. (2019) 'Introduction: Online Othering.' In: K. Lumsden and E. Harmer (eds) Online Othering: Exploring Violence and Discrimination on the Web. Basingstoke: Palgrave Macmillan.

othering in online contexts, and their perceptions of online abuse. Ruth Lewis, Mike Rowe and Claire Wiper discuss experiences of online abuse amongst women who are engaged in feminist politics. They use debates about Violence Against Women and Girls (VAWG) and hate crime to consider the continuities and breaks between online and offline victimisation, arguing that online abuse should be considered to be a form of VAWG and a hate crime but that describing online abuse as a form of hate obscures the complex emotional context when perpetrators are known to the victims, and because 'hate crime' has not reflected the intersectional nature of some offences which target victims' identities. Rikke Amundsen's contribution explores how women make sense of the risk of having their private sexual images (PSIs) shared without their consent. Her analysis focuses on the way that postfeminist ideas about individualism, free choice, and female empowerment influences women's accounts of this particular sexting related risk. Her findings suggest placing emphasis on making the right choices in terms of whom to trust effectively render themselves primarily responsible for their own risk mitigation therefore victims of such non-consensual sharing receive little empathy. John Whittle, Dave Elder-Vass and Karen Lumsden draw on semi-structured interviews and focus groups with boys and girls aged 11-16 years old to explore how 'banter' is a common form of social interaction within male peer groups interacting online and how tis can represent is a means of othering, and of performing and constructing hegemonic masculinity. The final chapter in this section by Rosalynd Southern and Emily Harmer draws on an inductive thematic analysis of 12,436 tweets to examine the extent to which abusive and more everyday forms of sexism, misogyny and racism pervade Twitter interactions between politicians and citizens. Their analysis identified four themes: gendered and racist abuse; silencing and dismissal; questioning intelligence and position; and 'benevolent' othering. 
Pre-print version of: Harmer, E. and Lumsden, K. (2019) 'Introduction: Online Othering.' In: K. Lumsden and E. Harmer (eds) Online Othering: Exploring Violence and Discrimination on the Web. Basingstoke: Palgrave Macmillan.

Section III includes three chapters which aim to highlight less mainstream experiences of othering that those which have previously been discussed in the literature or, indeed in the book itself. These contributions highlight the importance of taking an intersectional approach to online othering. Ben Colliver, Adrian Coyle and Marisa Silvestri provide a critical analysis of some ways in which transgender people are 'othered' online and details attempts to resist or challenge such othering. They analyse 1756 online comments made in response to ten YouTube videos concerning 'gender neutral toilets', and develop three recurring themes; 'Gender neutral toilets as sites of sexual danger'; 'Claiming victimhood: Gender neutral toilets as undermining the rights of cisgender people'; and 'The delegitimisation and othering of transgender people'. Herminder Kaur uses ethnography to explore the way that young people with physical disabilities make use of digital technology to explore their sexual identity and highlights the extent to which their access is policed by parental interventions which inadvertently other them by denying their sexuality. The final chapter in this section, by Nathan Kerrigan explores the ways residents of a rural community in the south of England use the internet to construct an online rural space through giving meaning to the forum as 'rural', and the extent to which this excludes and 'others' those with perceived differences, leading to targeted hate and victimisation for those individuals online.

Section IV, the final section of the book, focuses on the questions of how we should respond to, regulate, and police online spaces. Digital media corporations have typically been slow to act and respond to user concern regarding toxic online cultures, hate speech and abuse; while police agencies are faced with an ever-changing socio-technical landscape in terms of emerging social media technologies and apps, and therefore struggle to detect and prosecute those responsible. This section also demonstrates that digital technology can also be used to resist and challenge online othering. Jo Smith highlights how women have responded to instances of 
Pre-print version of: Harmer, E. and Lumsden, K. (2019) 'Introduction: Online Othering.' In: K. Lumsden and E. Harmer (eds) Online Othering: Exploring Violence and Discrimination on the Web. Basingstoke: Palgrave Macmillan.

online misogyny, including reporting these and/or resisting them via fight responses and 'digilante' actions. She further highlights that policing and regulating online misogyny is further complicated by the nature of online space, calls to respect freedom of speech, limited legislative provisions, and ambiguity over whether these behaviours are indeed 'criminal'. Phillipa Hall's chapter analyses the online othering of disabled people via hate speech on social media platforms. Hall argues that social and legal initiatives to confront online disability hate speech must address and contend with internet companies' business imperatives. She also argues that the tendency to conceptualise online and offline as distinct spaces further legitimises calls for the continued deregulation of online space/s in relation to disability hate speech. Brianna O’Shea, Roberta Julian, Jeremy Prichard and Sally Kelty draw on draws on findings from interviews with police investigators and prosecutors on the challenges for policing cyberstalking to two examine how cyberstalking is investigated by the police in Australia. They argue that for police investigators and prosecutors to be proactive in the policing of cyberstalking, risk assessments must constantly adapt to changing technologies and their implications for interpersonal relationships. The final chapter of this volume by Alex Black, Karen Lumsden and Lee Hadlington discusses police officer and civilian staff views of reports of interpersonal cybercrime in England. The authors demonstrate how police officers' notions about the 'ideal victim' of online crime frames their response to public reports of online harassment and cybercrime. The police response results in victim-blaming of online users who are viewed as making themselves vulnerable to cybercrime and hate via their occupation of, and refusal to withdraw from, particular virtual spaces.

\section{References}

Alcoff, L. (1991). The problem of speaking for others. Cultural Critique, Winter, 5-32.

Alexander, C. (2009). STUART HALL AND 'RACE'. Cultural Studies, 23 (4): 457-482. 
Pre-print version of: Harmer, E. and Lumsden, K. (2019) 'Introduction: Online Othering.' In: K. Lumsden and E. Harmer (eds) Online Othering: Exploring Violence and Discrimination on the Web. Basingstoke: Palgrave Macmillan.

Allen, C. (2010). Islamophobia. Farnham: Ashgate.

Awan, I. (ed.), (2016). Islamophobia in Cyberspace. London: Routledge.

Bates, L. (2014). Everyday Sexism. UK: Simon \& Schuster.

Bauman, Z. (1991). Modernity and Ambivalence. Cambridge: Polity Press.

Berridge, S. and Portwood-Stacer, L. (2015). Introduction: feminism, hashtags and violence against women and girls. Feminist Media Studies, 15 (2): 341.

Bessire, L. and Bond, D. (2017). The rise of Trumpism. Hot Spots, Cultural Anthropology. URL (accessed 13 October 2018): https://culanth.org/fieldsights/1030-the-rise-of-trumpism Bhabha, H.K. (1994). The Location of Culture. New York: Routledge.

Billig, M. (2002). Henri Tajfel's 'cognitive aspects of prejudice' and the psychology of bigotry. British Journal of Social Psychology, 41: 171-188.

Binns, A. (2012). Don't feed the trolls! Journalism Practice, 6 (4): 547-562.

Bishop, J. (2013). The art of trolling law enforcement: a review and model for implementing 'flame trolling' legislation enacted in Great Britain (1981-2012). International Review of Law, Computers and Technology, 27 (3): 301-318.

Bowles, N. (2018). Thermostats, locks and lights: Digital tools of domestic abuse. The New $\begin{array}{llllll}\text { York } & \text { Times. } & \text { URL } & \text { (accessed } & \text { October }\end{array}$ https://www.nytimes.com/2018/06/23/technology/smart-home-devices-domestic-abuse.html

Brons, L. (2015). Othering, an analysis. Transcience, 6 (1): 69-90.

Buchwald, E., Fletcher, P.R. and Roth, M. (eds.), (2005). Transforming a Rape Culture. Minneapolis, MN: Milkweed Editions.

Chatterjee, R., Doerfler, P., Orgad, H., Havron, S., Palmer, J., Freed, D., Levy, K., Dell, N., McCoy, D. and Ristenpart, T. (2018). The spyware used in intimate partner violence. 2018 IEEE Symposium on Security and Privacy (SP). URL (accessed 13 October 2018): https://ieeexplore.ieee.org/abstract/document/8418618 
Pre-print version of: Harmer, E. and Lumsden, K. (2019) 'Introduction: Online Othering.' In: K. Lumsden and E. Harmer (eds) Online Othering: Exploring Violence and Discrimination on the Web. Basingstoke: Palgrave Macmillan.

Citron, D.K. (2016). Hate Crimes in Cyberspace. Cambridge, MA: Harvard University Press. Cixous, H. and Clement, C. (1975). The Newly Born Woman. Minneapolis: University of Minnesota Press.

Collins, P.H. (1991[1986]). Learning from the outsider within: The sociological significance of black feminist thought. In: M.M. Fonow and J.A. Cook (eds.), Beyond Methodology: Feminist Scholarship as Lived Experience (35-59). Bloomington: Indiana University Press.

Collins, P.H. (1998). It's all in the family: Intersections of gender, race, and nation. Hypatia, 13: $62-82$.

Crawford, A. (2017). Facebook failed to remove sexualised images of children. BBC News. URL (accessed 20 October 2018): https://www.bbc.co.uk/news/technology-39187929

Crenshaw, K. (1989). Demarginalizing the intersection of race and sex: A black feminist critique of antidiscrimination doctrine, feminist theory and antiracist politics. University of Chicago Legal Forum, 1 (8): 139-167.

Crenshaw, K. (1991). Mapping the margins: Intersectionality, identity politics, and violence against women of color. Stanford Law Review, 43 (6): 1241-1299.

Cuthbertson, A. (2018). Pride month 2018: YouTube runs 'anti-LGBT ads' while demonetising transgender videos. The Independent. URL (accessed 20 October 2018): https://www.independent.co.uk/life-style/gadgets-and-tech/news/pride-month-2018-youtube$\underline{\text { anti-lgbt-ads-demonetising-transgender-gay-videos-a8386181.html }}$

De Beauvoir, S. (1976[1949]). The Second Sex. Paris: Gallimard.

Devine, D. (2018). Hate crime did spike after the referendum - even allowing for other factors. Brexit, LSE. URL (accessed 13 October 2018): http://blogs.lse.ac.uk/brexit/2018/03/19/hatecrime-did-spike-after-the-referendum-even-allowing-for-other-factors/

Dodge, A. (2015). Digitizing rape culture: Online sexual violence and the power of the digital photograph. Crime, Media, Culture 12 (1): 65-82. 
Pre-print version of: Harmer, E. and Lumsden, K. (2019) 'Introduction: Online Othering.' In: K. Lumsden and E. Harmer (eds) Online Othering: Exploring Violence and Discrimination on the Web. Basingstoke: Palgrave Macmillan.

Donarth, J.S. (1999). Identity and deception in the virtual community. In: M.A. Smith and P. Kollock (eds.), Communities in Cyberspace (29-59). London: Routledge.

Dow, J.B. (1996). Prime-Time Feminism. Philadelphia: University of Pennsylvannia Press.

Dragiewicz, M., Burgess, J., Matamoras-Fernandez, A., Salter, M. Suzor, N.P., Woodlock, D. and Harris, B. (2018). Technology facilitated coercive control: Domestic violence and the competing roles of digital media platforms. Feminist Media Studies, ifirst. doi https://doi.org/10.1080/14680777.2018.1447341

Eagle, R.B. (2015). Loitering, lingering, hashtagging: women reclaiming public space via \#BoardtheBus, \#StopStreetHarrassment, and the \#EverydaySexism Project. Feminist Media Studies, 15 (2): 350-353.

Easter, B. (2018). 'Feminist_Brevity_in_light_of_masculine_long-windedness:' Code, space, and online misogyny. Feminist Media Studies, 18 (4): 675-685.

Essed, P. (1991). Understanding Everyday Racism. London: Sage.

Feldman, M. and Littler, M. (2014). Tell MAMA reporting 2013/14 anti-muslim overview, analysis and 'cumulative extremism'. Centre for Fascist, Anti-Fascist and Post-Fascist Studies, Teeside University, UK. URL (accessed 11 March 2016): http://tellmamauk.org/wpcontent/uploads/2014/07/finalreport.pdf

Fine, M. (1994). Working the hyphens: Reinventing self and other in qualitative research. In: N.K. Denzin and Y.S. Lincoln (eds.), Handbook of Qualitative Research. London: Sage.

Fraser, N. (1990). Rethinking the public sphere: A contribution to the critique of actually existing democracy. Social Text, 25-26: 56-80.

Fuchs, C. (2009). Information and communication technologies and society: A contribution to the critique of the political economy of the internet. European Journal of Communication, 24 (1): 69-87.

Fuchs, C. (2017). Social Media: A Critical Introduction, 2nd Edition. London: Sage. 
Pre-print version of: Harmer, E. and Lumsden, K. (2019) 'Introduction: Online Othering.' In: K. Lumsden and E. Harmer (eds) Online Othering: Exploring Violence and Discrimination on the Web. Basingstoke: Palgrave Macmillan.

Gerard, J.F. and Whitfield, K.C. (2016). The experiences of victims of online Islamophobia. In: I. Awan (ed.) Islamophobia in Cyberspace. London: Routledge.

Gingrich, A. (2004). Conceptualizing identities. In: G. Bauman and A. Gingrich (eds.), Grammars of Identity/Alterity -A Structural Approach. Oxford: BergHahn.

Hall, S. (ed.), (1997). Representation: Cultural Representations and Signifying Practices. London: Sage.

Hall, S. (2000). The multicultural question. In: B. Hesse (ed.), Un/Settled Multiculturalisms. London: Zed Press.

Hardaker, C. (2010). Trolling in asynchronous computer mediated communication: From user discussions to academic definitions. Journal of Politeness Research, 6: 215-242.

Hardaker, C. and McGlashan, M. (2016). 'Real men don't hate women': Twitter rape Threats and group identity. Journal of Pragmatics, 91: 80-93.

Hawley, G. (2017). Making Sense of the Alt-Right. Columbia: Columbia University Press.

Herring, S.C. (1999). The rhetorical dynamics of gender harassment on-line. The Information Society, 15: 151-167.

Herring, S.C. (2003). Computer-mediated discourse. In: D. Schiffrin, D. Tannen and H.E. Hamilton (eds.), The Handbook of Discourse Analysis, 612-634. Oxford: Blackwell.

Herring, S.C., Job-Sluder, K., Scheckler, R. and Barab, S. (2002). Searching for safety online: Managing 'trolling' in a feminist forum. The Information Society, 18: 371-384.

Hill Collins, P. (1989). The social construction of black feminist thought. Signs, 14 (4): $745-$ 773.

Hill Collins, P. (1990). Black Feminist Thought: Knowledge, Consciousness, and the Politics of Empowerment. New York: Routledge.

Hill Collins, P. (1998). It's all in the family: Intersections of gender, race and nation. Hypatia, $13(3): 62-82$. 
Pre-print version of: Harmer, E. and Lumsden, K. (2019) 'Introduction: Online Othering.' In: K. Lumsden and E. Harmer (eds) Online Othering: Exploring Violence and Discrimination on the Web. Basingstoke: Palgrave Macmillan.

Hmielowski, J.D., Hutchens M.J. and Cicchirillo V.J. (2014). Living in an age of online incivility: Examining the conditional indirect effects of online discussion on political flaming. Information, Communication \& Society, 17 (10): 1196-1211.

hooks, b. (1990). Yearning: Race, Gender and Cultural Politics. Boston: South End Press.

Hutchens, M.J., Cicchirillo, V.J. and Hmielowski, J.D. (2015). How could you think that?!?!: Understanding intentions to engage in political flaming. New Media \& Society, 17 (8): 12011219.

ITV News. (2018). Twitter urged to do more to tackle abuse of disabled users. URL (accessed 20 October 2018): http:/www.itv.com/news/2018-02-20/twitter-charity-disabled-abuse/

Jackson, S., Prince, J. and Young, P. (1993). Science, medicine and reproductive technology: Introduction.' In: S. Jackson, (ed.), Women's Studies: A Reader. London: Harvester Wheatsheaf.

Jane, E.A. (2014a). 'You're a ugly, whorish, slut.' Feminist Media Studies, 14 (4): 531-546.

Jane, E.A. (2014b). 'Back to the kitchen, cunt': Speaking the unspeakable about online misogyny. Continuum, 28 (4): 558-570.

Jensen, S.Q. (2011). Othering, identity formation and agency. Qualitative Studies, 2 (2): 6378.

Keller J.M., Mendes K.D. and Ringrose, J. (2015). Speaking 'unthinkable things': Documenting digital feminist responses to rape culture. Journal of Gender Studies. Pre-print version. URL (accessed 14 March 2016): https://lra.le.ac.uk/handle/2381/33121

Kiesler, S., Zubrow, D, and Moses, A.M. (1985). Affect in computer-mediated communication: An experiment in synchronous terminal-to-terminal discussion. HumanComputer Interaction, 1 (1): 77-104.

Kitzinger, C. and Wilkinson, S. (1996). Theorizing representing the other. In: S. Wilkinson and C. Kitzinger (eds.), Representing the Other (1-32). London: Sage. 
Pre-print version of: Harmer, E. and Lumsden, K. (2019) 'Introduction: Online Othering.' In: K. Lumsden and E. Harmer (eds) Online Othering: Exploring Violence and Discrimination on the Web. Basingstoke: Palgrave Macmillan.

Khoja-Moolji, S. (2015). Becoming an 'intimate publics': Exploring the affective intensities of hashtag feminism. Feminist Media Studies, 15 (2): 347-350.

Komaromi, P. and Singh, K. (2016). Post-Referendum Racism and Xenophobia. London: PostRefRacism.

Korn, J.U. and Kneese T. (2015). Guest editors' introduction: Feminist approaches to social media research: History, activism, and values. Feminist Media Studies, 15 (4): 707-710. Lacan, J. (1977). Ecrits: A Selection. London: Tavistock.

Lea, M., O'Shea T., Fung P. and Spears R. (1992). 'Flaming' in computer-mediated communication: Observations, explanations, implications. In: M. Lea (ed.), Contexts of Computer-Mediated Communication (89-112). New York: Harvester Wheatsheaf.

Lister, R. (2004). Poverty. Cambridge: Polity Press.

Lumsden, K. (2019). Reflexivity: Theory, Method and Practice. London: Routledge.

Lumsden, K. and Morgan, H.M. (2017). Media framing of trolling and online abuse: Silencing strategies, symbolic violence and victim blaming. Feminist Media Studies, 17 (6): 926-940.

McGlynn, C., Rackley, E. and Houghton, R. (2017). Beyond 'revenge porn': The continuum of image-based sexual abuse. Feminist Legal Studies, 25(1): 25-46.

McLaren, P. (1994). White terror and oppositional agency. In: D.T. Goldberg (ed.), Multiculturalism: A Critical Reader. Oxford: Blackwell.

Mantilla, K. (2015). Gendertrolling. Westport, Connecticut: Praeger.

Marwick, A. and Ellison N.B. (2012). 'There isn't wifi in heaven': Negotiating visibility on Facebook memorial pages. Journal of Broadcasting \& Electronic Media, 56 (3): 378-400.

Massanari, A. (2017). \#Gamergate and the Fappening: How Reddit's algorithm, governance, and culture support toxic technocultures, New Media and Society, 19 (3): 329-346.

McQuail, D. (2010). Mass Communication Theory, 6th Edition. London: Sage. 
Pre-print version of: Harmer, E. and Lumsden, K. (2019) 'Introduction: Online Othering.' In: K. Lumsden and E. Harmer (eds) Online Othering: Exploring Violence and Discrimination on the Web. Basingstoke: Palgrave Macmillan.

Noble, S.U. (2018). Algorithms of Oppression: How Search Engines Reinforce Racism. New York: New York University Press.

O’Sullivan, P.B. and Flanagin, A.J. (2003). Reconceptualizing 'flaming' and other problematic messages. New Media \& Society, 5 (69): 69-94.

Papacharissi, Z. (2002). The virtual sphere: The internet as a public sphere. New Media and Society, 4 (1): 9-27.

Papacharissi, Z. (2004). Democracy online: civility, politeness, and the democratic potential of online political discussion. New Media and Society, 6 (2): 259-283.

Papacharissi, Z. (2016). The real-virtual dichotomy in online interaction: New media uses and consequences revisited. ANNALS of the International Communication Association, 29 (1): 216238.

Parker, D. and Song, M. (2006). New ethnicities online: Reflexive racialization and the internet. Sociological Review, 54 (3): 575-594.

Patai, D. (1991). US academics and third world women: Is ethical research possible? In: S. Berger Gluck and D. Patai (eds.), Women's Words: The Feminist Practice of Oral History. London: Routledge.

Petersen-Ellis, H. (2014). Mary reveals she befriended Twitter trolls following online abuse. The Guardian. URL (accessed 24 October 2018): https://www.theguardian.com/books/2014/aug/27/mary-beard-befriends-twitter-trolls-onlineabuse

Phillips, W. (2015). This is Why We Can't Have Nice Things. Cambridge, MA: MIT Press. Pickering, M. (2001). Stereotyping: The Politics of Representation. Basingstoke: Palgrave. Powell, A. and Henry, N. (2016). Policing technology-facilitated sexual violence against adult victims: police and service sector perspectives. Policing \& Society, 28(3): 291-307. Said, E. (1978). Orientalism. New York: Pantheon Books. 
Pre-print version of: Harmer, E. and Lumsden, K. (2019) 'Introduction: Online Othering.' In: K. Lumsden and E. Harmer (eds) Online Othering: Exploring Violence and Discrimination on the Web. Basingstoke: Palgrave Macmillan.

Sampson, E.E. (1993). Celebrating the Other: A Dialogic Account of Human Nature. London: Harvester Wheatsheaf.

Schwalbe, M. et al. (2000). Generic processes in reproduction of inequality: An interactionist analysis. Social Forces, 79 (2): 419-452.

Segal, L. (1994). Straight Sex: The Politics of Pleasure. London: Virago.

Shariff, S. and DeMartini, A. (2015). Defining the legal lines: eGirls and intimate images. In: J. Baley and V. Steeves (eds.), e Girls, eCitizens (281-306). Ottawa: University of Ottawa Press. Sills, S., Pickens, C., Beach, K., Jones, L., Calder-Dawe, O., Benton-Greig, P. and Gavey N. (2016). Rape culture and social media: Young critics and a feminist counterpublic. Feminist Media Studies, iFirst. DOI: 10.1080/14680777.2015.1137962

Spivak G.C. (1985). The Rani of Sirmur: An essay in reading the archives. History and Theory, 24 (3): $247-272$.

Squirrell, T. (2018a). New digital methods can be used to analyse linguistic terms and better understand Reddit communities. LSE US Centre. URL (accessed 13 October 2018): http://blogs.1se.ac.uk/usappblog/2017/08/02/new-digital-methods-can-be-used-to-analyselinguistic-terms-and-better-understand-reddit-communities/

Squirrell, T. (2017b). Linguistic data analysis of 3 billion Reddit comments shows the alt-right is getting stronger. Quartz. URL (accessed 13 October 2018): https://qz.com/1056319/whatis-the-alt-right-a-linguistic-data-analysis-of-3-billion-reddit-comments-shows-a-disparategroup-that-is-quickly-uniting/

Turkle, S. (1995). Life on the Screen: Identity in the Age of the Internet. New York: Simon and Schuster.

Ussher, J. (1991). Women's Madness: Misogyny or Mental Illness? London: Harvester Wheatsheaf. 
Pre-print version of: Harmer, E. and Lumsden, K. (2019) 'Introduction: Online Othering.' In: K. Lumsden and E. Harmer (eds) Online Othering: Exploring Violence and Discrimination on the Web. Basingstoke: Palgrave Macmillan.

Van Zoonen, L. (2002). Gendering the internet: Claims, controversies and cultures. European Journal of Communication 17 (1): 5-23.

Williams, S. (2015). Digital defense: Black feminists resist violence with hashtag activism.

Feminist Media Studies, 15 (2): 341-344. 